\title{
Social network addiction (SNA) related to anxiety among students at Kyaukse University, Mandalay Region, Myanmar
}

\author{
Kyaw Sann $\mathrm{Win}^{1}$, Thae Maung Maung ${ }^{2}$, Tun Tun Win ${ }^{3}$, Kyaw Soe ${ }^{4}$, Than Tun Sein ${ }^{5}$
}

${ }^{1}$ Assistant Lecturer; ${ }^{3}$ Lecturer; ${ }^{4}$ Professor; Preventive \& Social Medicine Department, Defence Services Medical Academy, Yangon, Myanmar. ${ }^{2}$ Research Scientist, Medical Research Division, Department of Medical Research (Lower Myanmar), Yangon, Myanmar. ${ }^{5}$ Honorary Professor, Anthropology Department, Yangon University, Yangon, Myanmar.

\begin{abstract}
Nowadays, Social Network (SN) is one of the essential tools of people especially young and adolescents. In consequence, there are so many controversial things on advantages and disadvantages of SN. In Myanmar, the rate of mobile phone users and internet users is on the increase today. This is a cross-sectional study conducted to the university students at Kyaukse University from June to November, 2015. In total 400 students who are aged between 16-23 years were randomly selected and interviewed with pretested structured questionnaires. The aim of this study is to determine the prevalence of Social Network Addiction (SNA) and the prevalence of anxiety. Furthermore, this study also found out SNA related to anxiety among students. Among the students, 110 students $(27.5 \%)$ addicted to SN and 146 students (36.5\%) suffered from anxiety. There is significant association between SNA and anxiety. Among the social network addicted users, $59.1 \%$ suffer from anxiety $\left(\chi^{2}=33.408, p<0.001\right)$. Most of the students who used SN addicted to SN. The students addicted to SN, duration of SN more than 3 years, SN using hours more than 4 hours per day, using Facebook and Google suffer from anxiety. According to the findings in this study, there is a positive association between SNA and anxiety. So parents, teachers and other authorities should be aware and involved in checking and controlling the internet use of the students. In addition, the similar researches should be encouraged in different population and different age groups to explore other side effects of SNA.
\end{abstract}

Keywords: Social Network, Addiction, Anxiety, University students, Myanmar

\section{Introduction}

Social Networking Sites (SNSs) are virtual communities where users can create individual public profiles, interact with real-life friends, and meet other people based on shared interests. ${ }^{1}$ SNS usage patterns from both consumer research and empirical research indicate that overall, regular SNS use has increased substantially over the last few years. ${ }^{1}$ SNSs are predominantly used for social purposes, mostly related to the maintenance of established offline networks, relative to individual ones. However, recent evidence suggests that individual may feel compelled to maintain their online social networks in a way that may, in some circumstances, lead to using SNSs excessively. ${ }^{1}$ The excessive use of online social networking may be problematic to young people. ${ }^{1}$ For this research work, Social Network Addiction (SNA) refers to someone spending too much time using Facebook, Twitter and other forms of social media - so much so that it interferes in other aspects of daily life. ${ }^{2}$

Globally, the total population is 7.219 billion and active internet users are 3.038 billion. ${ }^{3}$ Moreover, active social media users are 2.126 billion and this is the $29 \%$ of the world's population. ${ }^{3}$ According to regions, about $45.6 \%$ of the world internet users are from Asia and $54.4 \%$ are from other regions of the world. ${ }^{4}$ In Asia, the country which has the most internet users is China and the second is India. ${ }^{4}$ In Myanmar, the total population is 51.4 million and active internet users are 2.6 million which is $5 \%$ of the total population. ${ }^{3}$ Moreover, active social media users are 3.8 million. $^{3}$

\section{Practice Points}

- The excessive use of social networking may be problematic especially to young people.

- In this study, SNA prevalence is $27.5 \%$ and the prevalence of anxiety is $36.5 \%$ among the university students.

- Among the students who addicted to SN, about $60 \%$ suffer from anxiety.

- Moreover, the students who use SN more than 3 years, SN using hours more than 4 hours per day, using Facebook and Google suffer from anxiety.

- Media advocacy should be practiced to make people and policy maker aware of the seriousness of SNA and anxiety.

International estimates of internet addiction widely vary. In a multicenter study, the prevalence of adolescent's internet addiction was reported between $7.9 \%$ and $22.8 \%$. $^{5}$ SNA prevalence in China study showed that $34 \%$ of Chinese college students aged 19 to 28 suffered SNA. ${ }^{6}$ A study conducted in Iran revealed that prevalence of internet addiction among university students was $43.7 \%{ }^{7}$ Another study reported the internet addiction prevalence among Korean adolescents were $1.6 \%$ and $38 \%$ had the

Correspondence: Dr. Kyaw Sann Win, 25-Hinthada Street, Sann-chaung PO, Yangon 11111, Myanmar. Email: kyawsann3153.ks@gmail.com. 
potential for internet addiction. ${ }^{8} \mathrm{~A}$ review reported that the prevalence of internet addiction in the US youth was $26 \%$. $^{9}$ In fact, every one in eight US adults addicted to internet. ${ }^{10}$ Moreover, there are 1.44 billion Facebook users in the world. Among them, about 936 million people are $\log$ on Facebook daily. Among Facebook users, $50 \%$ of the young adults who are the age of between 18-24 years are logged on the Facebook in the morning daily. ${ }^{11}$ The data about the prevalence of internet addiction in Myanmar are not available yet.

Reports indicated that most of these conditions are highly prevalent among younger age group. The prevalence of adolescent's internet addiction was reported between $7.9 \%$ and $22.8 \% .^{5}$ About $50 \%$ of internet users who are aged between 18 and 25 are firstly logged in Facebook every morning as soon as they woke up. ${ }^{11}$ University students have wider and easier access to the internet connection by means of mobile devices. Therefore, they can easily log in to the social network sites wherever they go. As a consequence, the internet users do not need to be at home to use the internet. They can easily connect to the internet outside the houses such as in the cafes, restaurants, universities. ${ }^{12}$ Myanmar is also one of the countries with increasing trend in internet users. Mobile internet users study in Myanmar indicated that $72 \%$ of the participants were used mobile internet daily. ${ }^{13}$ Most of the participants $38 \%$ are the age of between 16-24 years old. ${ }^{13}$ In Myanmar, however, the data for SNA and related to anxiety has not been investigated widely yet. This study was conducted with the specific objectives of assessing the prevalence of SNA, the prevalence of anxiety and determining the SNA related to anxiety.

\section{Conceptual Framework}

Figure 1 shows the conceptual framework of the study. SNA can lead to physical disorders, social disorders and psychological disorders. Physical disorders mean sleep disturbance, back strain, eye strain etc., and social disorders mean poor academic performance and family problems etc. Psychological disorders mean anxiety, stress and depression. In this study, it was tried to assess the relationship between SNA and anxiety which is one of the psychological disorders.

\section{Materials and methods}

\section{Sampling method and sampling procedure}

In Kyaukse University, there are total 11 majors and the number of total students is 4764 . Among them, eight majors were randomly chosen and these majors are History, Geography, Geology, Chemistry, Physics, Mathematics, Zoology and Botany. The total number of students who used SN in these eight majors is 4097. Then, sample size is randomly chosen from these eight majors based on probability proportionate to size. So, the sample size is collected as 6 out of $54(1.31 \%)$ from history major, 8 out of $74(1.8 \%)$ from geography major, 41 out of 444 (10.83\%) from geology major, 86 out of $874(21.33 \%)$ from chemistry major, 86 out of 885 from physics major, 89 out of $898(21.9 \%)$ from mathematics, 44 out of $455(11.1 \%)$ from zoology and 41 out of $413(10.8 \%)$ from botany. Then, the total sample size is 400 .

\section{Data collection tool and technique}

Quantitative data collection method involving face to face interview applying pre-tested structured questionnaire was used. Internet Addiction Scale and Self Rating Anxiety Scale were used in this study.

\section{Internet Addiction Test}

Internet addiction test was assessed by Young's 20 items Internet Addiction Test (IAT) ${ }^{14}$ which was modified by Kittinger et al. ${ }^{15}$ in 2012 . Total score of this scale was 100 and cut-off point was 49 :

$$
\begin{array}{ll}
20-49 & =\text { Normal Internet user } \\
50-100 & =\text { Addicted Internet user }
\end{array}
$$

Figure 1: Conceptual Framework of the study

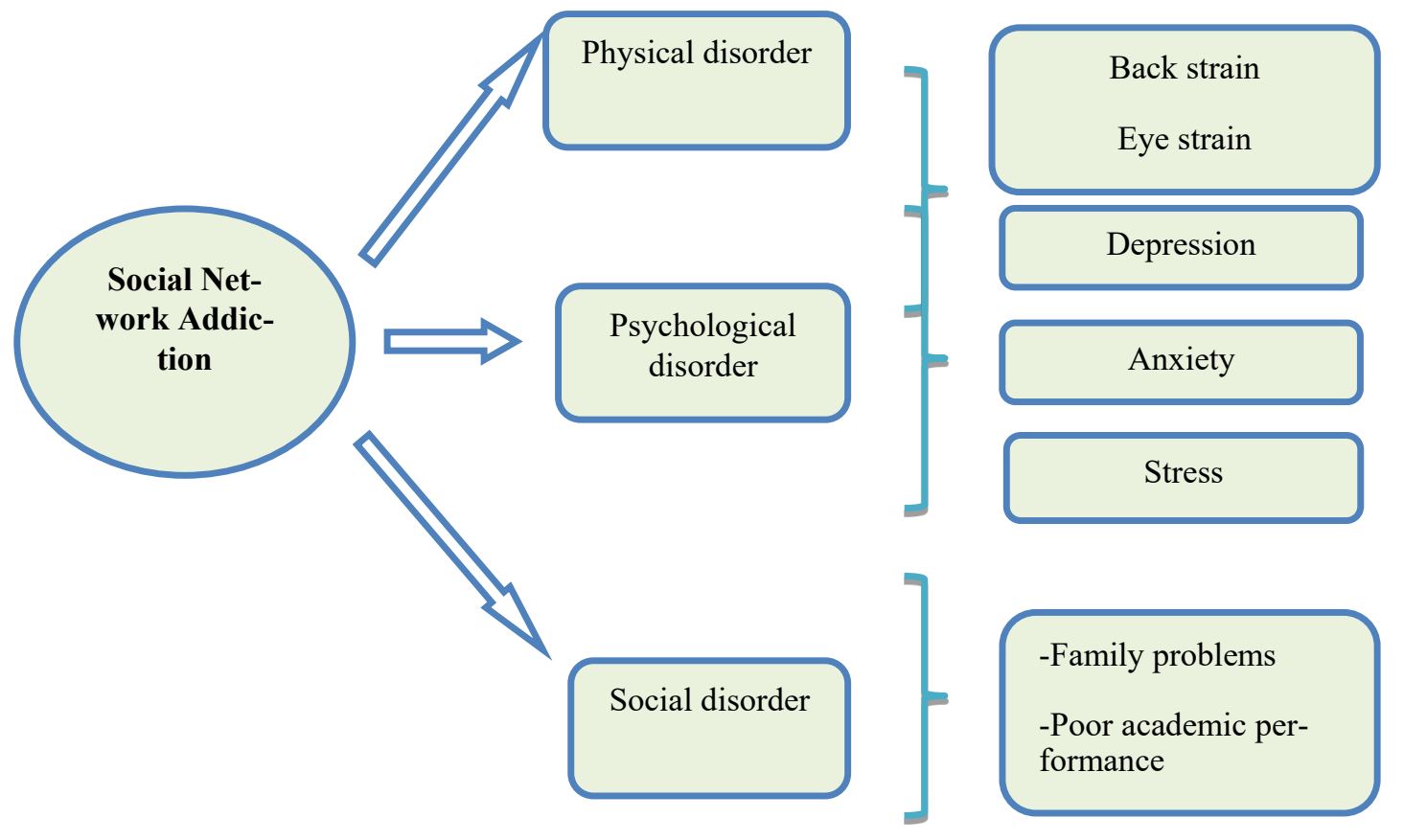




\section{Self-Rating Anxiety Scale (SARS)}

This scale is designed to measure the state anxiety as experienced by the patient by giving his own ratings on four-point scale $0,1,2$, and 3 . The final 24 items check-list was developed by Dr. Ohn Hlaing and Dr. Ohn Kyaw from the 82-items check-list of anxiety complaints collected on the basis of anxiety scales developed in other countries, text-books and the authors' account of patients with anxiety states. ${ }^{16} \mathrm{~A}$ crossvalidation study was done on 50 clinically diagnosed anxiety cases and 52 normal individuals by Dr. Ohn Hlaing and Dr. Ohn Kyaw. ${ }^{16}$ By taking the score 9 as the cut-off point, $98 \%$ of clinically anxious patients were correctly classified by this scale, misclassification rate was only 2 false negatives. Severity of anxiety classified by the scores was validated against the clinician's rating of anxiety, and the validity computed in contingency coefficient was found to be 0.64 ( $p$ $<0.001)$. A split half reliability study by content was done on the validation sample, and the reliability coefficient calculated in spearman's rho was 0.86 after correction by Spearman-Brown formula. ${ }^{16}$

$\begin{array}{ll}\text { - } \text { Total score } & =72 \\ \text { - Cut-off point } & =9 \\ \text { - Non-anxious group } & =0-9 \\ \text { - Anxious group } & =10-72\end{array}$

Before data collection, Cronbach's alpha test was calculated for all questionnaires such as Internet Addiction Scale and Self-Rating Anxiety Scale that used in this study. Cronbach's alpha for Internet Addiction Scale was 0.926 and Self-Rating Anxiety Scale was 0.930 for the population.

\section{Data management and analysis}

The coding in the questionnaires form was checked and double data entry and validation of two data files was done by using Epidata software version 3.1. Data was checked for completeness, errors and inconsistency after data collection. The background information and social network utilization patterns, prevalence of social network addiction and prevalence of anxiety of the respondents were firstly presented by using descriptive statistics such as frequency and percent. The association between social network addiction, anxiety, background information and social network utilization patterns were determined by Chi-square test and $p$ value of equal or less than 0.05 was taken as the significant level by using SPSS version 16.0.

\section{Ethical consideration}

Ethical consideration was obtained from Post- Graduate Board of Studies Defence Services Medical Academy (DSMA). After obtaining the participation of the students with informed consent form, the students were interviewed by questionnaires.

\section{Results}

Table 1 shows the details of socio-demographic characteristics of the respondents. Regarding sociodemographic characteristics of the respondents, 289 respondents $(72.2 \%)$ were adolescent who were age between $16-19$ year old and the rest $111(27.8 \%)$ were young adult who are the age of between $20-23$ year old. Among the students, 166 students $(41.5 \%)$ are males and 234 students $(58.5 \%)$ are females. Regarding years of SN used, $31(7.8 \%)$ of the students have used SN for more than 3 years, $82(20.5 \%)$ have used 2 years, $150(37.5 \%)$ have used SN from 6 months to 1 year and $137(34.2 \%)$ have used SN for less than 6 months. According to SN using hours per day, about 161 $(40.2 \%)$ are spent on $\mathrm{SN}$ for less than 1 hour, 118 $(29.5 \%)$ of the respondents are used about 1 hour a day for SN, 63 (15.8\%) spent on SN for about 2 hours, $35(8.8 \%)$ spent on SN for about 3 hours and only $5.8 \%$ of the respondents spent about 4 hours and above for SN. Regarding phone bill, 388 students $(97 \%)$ of the respondents are cost less than 30000 kyats a month for phone bill and $12(3.0 \%)$ of the respondents are cost more than 30000 kyats for it. Moreover, 295 students $(73.8 \%)$ are using Facebook and 57 students (14.2\%) are using Google.

Regarding the prevalence of SNA and anxiety among the respondents, $110(27.5 \%)$ of the respondents are SN addicted users and 146 students $(36.5 \%)$ of the respondents suffer from anxiety (Table 2 ).

Table 3 shows the association between sociodemographic factors, SNA and anxiety. According to duration of SN used, about $46(33.6 \%)$ of the students who used SN for less than 6 months, about 43 $(28.7 \%)$ of the students who used $\mathrm{SN}$ between 6 months and 1 year, about $34(41.5 \%)$ of the students who used SN about 2 years and about $23(74.2 \%)$ of the students who used SN more than 3 years suffer

Table 1: Socio-demographic characteristics of the students $(\mathrm{n}=400)$

\begin{tabular}{|l|c|}
\hline Socio-demographic factors & Frequency (\%) \\
\hline Age & $111(27.8 \%)$ \\
\hline Young adult(20-23 yr) & $289(72.2 \%)$ \\
\hline Adolescent(16-19 yr) & $166(41.5 \%)$ \\
\hline Sex & $234(58.5 \%)$ \\
\hline Male & $137(34.2 \%)$ \\
\hline Female & $150(37.5 \%)$ \\
\hline Duration of social network used \\
\hline$<6$ months & $82(20.5 \%)$ \\
\hline 6 months-1 year & $31(7.8 \%)$ \\
\hline About 2 years & $161(40.2 \%)$ \\
\hline About 3 years and above & $118(29.5 \%)$ \\
\hline Social Network using hours per day \\
\hline$<1$ hour & $63(15.8 \%)$ \\
\hline About 1-2 hours & $35(8.8 \%)$ \\
\hline About 2-3 hours & $23(5.8 \%)$ \\
\hline About 3-4 hours & $12(3 \%)$ \\
\hline$>4$ hours & $388(97 \%)$ \\
\hline Phone bill per month & $295(73.8 \%)$ \\
\hline$\geq 30000$ kyats & $57(14.2 \%)$ \\
\hline$<30000$ kyats
\end{tabular}

Table 2: SNA and anxiety prevalence among students $(\mathrm{n}=400)$

\begin{tabular}{|l|c|}
\hline Prevalence & Respondents (\%) \\
\hline SNA & $110(27.5 \%)$ \\
\hline Addicted user & $290(72.5 \%)$ \\
\hline Normal user & \\
\hline Anxiety & $146(36.5 \%)$ \\
\hline Anxious group & $254(63.5 \%)$ \\
\hline Non-anxious group &
\end{tabular}


Table 3: Association between socio-demographic factors, SNA and anxiety $(n=400)$

\begin{tabular}{|c|c|c|c|c|}
\hline \multirow[t]{2}{*}{ Variables } & \multicolumn{2}{|c|}{$\begin{array}{c}\text { Anxiety } \\
\text { Frequency }(\%)\end{array}$} & \multirow[t]{2}{*}{$\chi^{2}$} & \multirow[t]{2}{*}{$p$ value } \\
\hline & $\mathbf{A G}$ & NAG & & \\
\hline $\begin{array}{l}\text { Age } \\
\text { Young adult(20-23yrs) } \\
\text { Adolescent(16-19yrs) }\end{array}$ & $\begin{array}{l}49(44.1 \%) \\
97(33.6 \%)\end{array}$ & $\begin{array}{c}62(55.9 \%) \\
192(66.4 \%)\end{array}$ & 3.873 & 0.49 \\
\hline $\begin{array}{l}\text { Sex } \\
\text { Male } \\
\text { Female } \\
\end{array}$ & $\begin{array}{l}67(40.4 \%) \\
79(33.8 \%)\end{array}$ & $\begin{array}{c}99(59.6 \%) \\
155(66.2 \%)\end{array}$ & 1.826 & 0.177 \\
\hline $\begin{array}{l}\text { Duration of social network used } \\
<6 \text { months } \\
6 \text { months }-1 \text { year } \\
\text { About } 2 \text { years } \\
>3 \text { years }\end{array}$ & $\begin{array}{l}46(33.6 \%) \\
43(28.7 \%) \\
34(41.5 \%) \\
23(74.2 \%)\end{array}$ & $\begin{array}{c}91(66.4 \%) \\
107(71.3 \%) \\
48(58.5 \%) \\
8(25.8 \%)\end{array}$ & 24.35 & $<0.001$ \\
\hline $\begin{array}{l}\text { Social network using hours per day } \\
<1 \text { hour } \\
\text { About } 1-2 \text { hours } \\
\text { About } 2-3 \text { hours } \\
\text { About } 3-4 \text { hours } \\
>4 \text { hours }\end{array}$ & $\begin{array}{l}46(28.6 \%) \\
42(35.6 \%) \\
23(36.5 \%) \\
20(57.1 \%) \\
15(65.2 \%)\end{array}$ & $\begin{array}{l}115(71.4 \%) \\
76(64.4 \%) \\
40(63.5 \%) \\
15(42.9 \%) \\
8(34.8 \%)\end{array}$ & 19.03 & 0.001 \\
\hline $\begin{array}{l}\text { Phone bill/month } \\
\geq 30000 \text { kyats } \\
<30000 \text { kyats }\end{array}$ & $\begin{array}{c}8(66.7 \%) \\
138(35.6 \%)\end{array}$ & $\begin{array}{c}4(33.3 \%) \\
150(64.4 \%)\end{array}$ & 4.857 & 0.028 \\
\hline $\begin{array}{l}\text { Facebook } \\
\text { Yes } \\
\text { No }\end{array}$ & $\begin{array}{l}118(40 \%) \\
28(26.7 \%)\end{array}$ & $\begin{array}{l}177(60 \%) \\
77(73.3 \%)\end{array}$ & 5.94 & 0.015 \\
\hline $\begin{array}{l}\text { Google } \\
\text { Yes } \\
\text { No }\end{array}$ & $\begin{array}{c}28(49.1 \%) \\
118(34.4 \%)\end{array}$ & $\begin{array}{l}29(50.9 \%) \\
225(65.6 \%)\end{array}$ & 4.57 & 0.033 \\
\hline $\begin{array}{l}\text { SNA Group } \\
\text { Addicted User } \\
\text { Normal User }\end{array}$ & $\begin{array}{l}65(59.1 \%) \\
81(27.9 \%)\end{array}$ & $\begin{array}{c}45(40.9 \%) \\
209(72.1 \%)\end{array}$ & 33.408 & $<0.001$ \\
\hline
\end{tabular}

from anxiety $\left(\chi^{2}=24.351, p-<0.001\right)$. This means that the duration of SN used and anxiety are statistically significantly associated with anxiety.

According to social network using hours, about 46 $(28.6 \%)$ of the students who used SN for less than 1 hour per day, about $42(35.6 \%)$ of the students who used SN between 1 and 2 hours per day, about $23(36.5 \%)$ of the students who used SN about 2-3 hours per day, about 20 $(57.1 \%)$ of the students who used SN more than between 3-4 hours per day and $15(65.2 \%)$ of the students who used SN about more than 4 hours per day suffer from anxiety $\left(\chi^{2}=19.03, p-0.001\right)$. Thus, it can be assumed that the prolong duration of $\mathrm{SN}$ used are statistically significantly associated with anxiety.

According to phone bill per month, $8(66.7 \%)$ of the respondents who are cost 30000 kyats and $138(35.6 \%)$ of the respondents who are cost less than 30000 kyats a month for phone bill suffer from anxiety. $\left(\chi^{2}=4.857, p\right.$ 0.028 ). So it can be assumed that the students who are cost more than 30000 kyats for phone bill per month are statistically significantly associated with anxiety.

According to Facebook usage, $118(40 \%)$ of the respondents are suffer from anxiety $\left(\chi^{2}=5.94, p\right.$ $0.015)$.According to Google usage, $28(49.1 \%)$ of the respondents who use Google suffer from anxiety $\left(\chi^{2}=4.57, p-0.033\right)$. This mean that the Facebook and Google usage are statistically associated with anxiety.

Regarding SNA, 65 students (59.1\%) of SN addicted users suffer from anxiety and SNA are statistically significantly associated with anxiety. Thus, it can be assumed that anxiety is associated with SNA.

\section{Discussion}

The excessive use of SNs and SNA related to complications have become a problematic to people especially youth. This study is aimed to find out the prevalence of SNA, associating factors of SNA and SNA related anxiety among the university students.

In this study, the prevalence of SNA is about $28 \%$ and the anxiety is about $37 \%$. In the study of Azher et $a l .,{ }^{17}$ the prevalence of internet addiction is $36.5 \%$. In an another study, SNA prevalence in China study showed that $34 \%$ of Chinese college students aged 19 to 28 years are suffered SNA. ${ }^{6}$ A study conducted in Iran revealed that prevalence of internet addiction among university students was $43.7 \%{ }^{7}$ Another study reported that the internet addiction prevalence among Korean adolescents were $1.6 \%$ and $38 \%$ had the potential for internet addiction. ${ }^{8}$ In a multicenter study, the prevalence of adolescent's internet addiction was reported between $7.9 \%$ and $22.8 \%{ }^{5}$ Moreover, a review reported that the prevalence of internet addiction in the US youth was $26 \%{ }^{9}$

Internet addiction can contribute to $45 \%$ of depression, $40 \%$ of the anxiety and $40 \%$ of the stress. ${ }^{18}$ One of the worst effects of internet addiction is anxiety, stress and depression. Increase 
in using internet makes some problems that one of them is anxiety. ${ }^{19}$ In the study of Nima et al. ${ }^{19}$ it was revealed that there exists a positive and significant correlation between the level of anxiety and internet addiction. ${ }^{19}$ According to the study of Razieh et al., ${ }^{20}$ it was also found that internet users have a higher anxiety level than non-internet users $(80.75 \%$ and $28.5 \%)$ respectively. In this study, about $60 \%$ of SN addicted users account for anxiety. Moreover, there was also statistically significant association between SNA and anxiety in this study $(p<0.001)$.

Among the students, about $67 \%$ of the students who are cost more than 30000 kyats a month for phone bill suffer from anxiety and the students who are cost more than 30000 kyats a month for phone bill have a higher risk to occur anxiety than that of less than 30000 kyats a month in this study $\left(\chi^{2}=4.857, p-0.028\right)$. In the study of Khang et $a .^{21}$ it was identified that compulsive anxiety as a factor in mobile phone addiction. University students have wider and easier access to the internet connection by means of mobile devices. ${ }^{12}$ Drouin et al. ${ }^{22}$ mentioned that text messaging addiction and phantom vibrations might just be contemporary versions of social sensitivity or social anxiety.

According to duration of SN used, about $75 \%$ of the students who used SN for more than 3 years suffer from anxiety $\left(\chi^{2}=24.351, p-<0.001\right)$. Furthermore, about $65 \%$ of the students who used SN for more than 4 hours per day suffer from anxiety $(\chi=19.03, p$ - 0.001). In another study, there are 1.44 billion Facebook users in the world. Among them, about 936 million people are log on Facebook daily. Among Facebook users, 50\% of the young adults who are the age of between 18-24 logged on to the Facebook in the morning daily. ${ }^{11}$ In the study of Sharif et al., ${ }^{23}$ Facebook users who use Facebook more than 4 hours per day are likely to addict Facebook. Moreover, it is said that internet addiction account for $40 \%$ of anxiety in the study of Akin et al. ${ }^{18}$ So, it can be assumed that using Facebook can lead to SNA and SNA can be associated with anxiety. In this study, about $40 \%$ of the students who used Facebook suffer from anxiety and Facebook users have more risk to suffer from anxiety than non-Facebook user $\left(\chi^{2}=5.94, p-0.015\right)$. Among the students, about $50 \%$ of the students who used Google suffer from anxiety and Google users have more risk to suffer from anxiety than non-Google users $\left(\chi^{2}=4.57, p-0.033\right)$.

There have some limitations in this study. The first one is the mental health status of the students and other associated factors of mental health could not be assessed before the study. Another one is that other psychological side effects of SNA such as depression and stress could not be explored in the study. And the last one is that the study population in this study was selected from Kyaukse University and it may not be represented the whole university students in Myanmar.

\section{Conclusion}

This study has contributed to understanding of the relationship between SNA and anxiety. Among the students, the prevalence of anxiety is about $37 \%$ and some factors such as SNA, duration of SN used, SN using hours, phone bill, using Facebook and Google are risk factors for anxiety. Regarding SNA, the prevalence of SNA is $27.5 \%$ and about $60 \%$ of SNA students suffer from anxiety. Besides, there is positive association between SNA and anxiety $\left(\chi^{2}=33.408, p-<0.001\right)$. It is consisted with the studies of Azher et al. ${ }^{17}$ and Akin et $a l .{ }^{18}$ SNA and its related problems should be considered as a serious problem among the adolescents. Based on the findings of this study, it is necessary for adolescents and young adults to be educated concerning with the advantages and disadvantages of SN in order to prevent from SNA. Moreover, because SNA can contribute a negative impact on every age group, similar research should be performed in different age groups.

\section{Competing interest}

The authors declare that they have no competing interests.

\section{References}

1. Kuss DJ, Griffiths MD. Online Social networking and addiction - a rewiew of the psychological literature. Int J Env Res Public Health 2011; (8).

2. Walker L. What is Social Networking Addiction? 2015. https://www.lifewire.com/what-is-social -networking-addiction (accessed July 2015)

3. Internet Live Stats 2015. Internet Users Around The World. http://www.Internetlivestats.Com/stats/ htm (accessed July 2015)

4. Internet World Stats 2014. http:// www.Internetworldstats.Com/stats/htm (accessed July 2015)

5. Tsitsika A, Janikian M, Schoenmakers TM, Tzavela EC, Olafsson K, Wójcik S, et al. Internet addictive behavior in adolescence: a crosssectional study in seven European countries. Cyberpsychol Behav Soc Netw 2014;17(8):52835.

6. Wan C. Gratifications and loneliness as predictors of campus-SNS websites addiction \& usage pattern among Chinese collage students. Hong Kong: Chinese University of Hong Kong, 2009.

7. Hashemain A, Moghadam AD, Delpisheh A, Moghadam AD. Prevalence of internet addiction among university students in Ilam: a crosssectional study. Int J Epidemiol Res 2014;1(1):915 .

8. Kim K, Ryu E, Chon MY, Yeun EJ, Choi SY, Seo JS, Nam BW. Internet addiction in Korean adolescents and its relation to depression and suicidal ideation: a questionnaire survey. Int $J$ Nurs Stud 2006;43(2): 185-95.

9. Moreno MA, Jelenchick L, Cox E, Young H, Christakis DA. Problematic internet use among US youth: a systematic review. Arch Pediatr Adolesc Med 2011;165(9):797-805.

10. Aboujaoude E, Koran LM, Gamel N, Large MD, Serpe RT. Potential markers for problematic internet use: a telephone survey of 2,513 adults. CNS Spectr 2006;11(10):750-5.

11. World Facebook Statistics. The Top 20 Valuable Facebook Statistics, 2015. http://zephoria.com/ top-20-valuable-facebook-statistics (accessed July 2015) 
12. Teke R. A Comparison of Facebook Addiction between Social and Hard Sciences' Students. Master of Arts in Communication and Media Studies, Eastern Mediterranean University, 2011.

13. Hill H. Mobile Internet users in Myanmar. On device research, $2014 . \quad$ https:// ondeviceresearch.com/blog/myanmar-mobileinternet-report (accessed July 2015)

14. Young K. Internet Addiction Scale 1998. http:// www.globaladdiction.org (accessed July 2015)

15. Kittinger R, Correia CJ, Irons JG. Relationship between Facebook use and problematic Internet use among college students. Cyberpsychol Behav Soc Netw 2012;(15):324-7.

16. Ohn-Kyaw, Ohn-Hlaing. A Psychiatric Interview Schedule-Colleague Questionnaire. Myanmar, 1980.

17. Azher M, Khan RB, Salim M, Bilal M, Hussain A, Haseeb M. The Relationship between Internet Addiction and Anxiety among students of University of Sargoda. Int Hum Soc Sci 2014;4 (1): 291-2.
18. Akin A, Iskender M. Internet Addiction and Depression, Anxiety and Stress. Int Online J Educ Sci 2011;3(1):138-48.

19. Nima N. World academy of science, engineering and technology 2012. http:/waset.org/Publications/ $\underline{\text { XLM}} \mathrm{id}=1656 \& \mathrm{t}=\mathrm{endnote}($ accessed (accessed July 2015)

20. Razieh J, Ali G, Zaman A, Narjess khatoon S. The relationship between internet addiction and anxiety in the university students. Interdiscipl $J$ Cont Res Bus 2012;4(1):942-9.

21. Khang $\mathrm{H}$, Woo HJ, Kim JK. Self as an antecedent of mobile addiction. Int $J$ Mobile Commun 2012;10(1):65-84

22. Drouin M, Kaiser DK, Miller DA. Phantom vibrations among undergraduates: Prevavence and associated psychological characteristics. Comput Hum Behav 2012; 28:1490-6.

23. Sharifah SZ, Siti ZO, Jusang B, Mohd NO. Facebook addiction among female university students. Revista De Administratie Publica Si Politici Sociale 2011;2(7):95-109. 